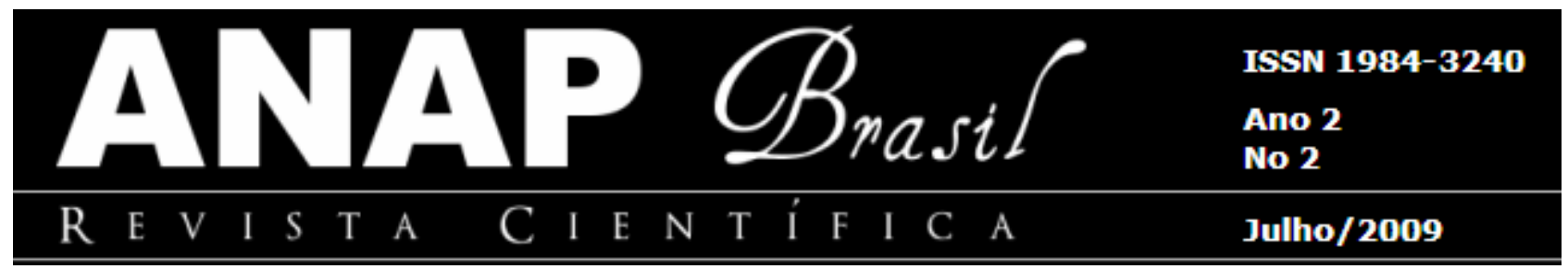

\title{
A BIOGRILAGEM E SEUS IMPACTOS NOS PAÍSES EM DESENVOLVIMENTO: UMA DISCUSSÃO NECESSÁRIA
}

Claudia Rosa Acevedo ${ }^{1}$

Jouliana Jordan Nohara ${ }^{2}$

José Luís Garcia Hermosilla ${ }^{3}$

\section{Ethel Cristina Chiari da Silva ${ }^{4}$}

RESUMO: O objetivo deste ensaio teórico é discutir a questão da biogrilagem e seus impactos sobre as economias em desenvolvimento, por meio do levantamento de questões consideradas importantes do ponto de vista socio-ambiental, e que merecem ser discutidas em maior profundidade tanto na esfera acadêmica quanto do poder público, em função dos impactos e das conseqüências econômicas e sociais das práticas de apropriação indevida de recursos genéticos e de conhecimentos tradicionais, por parte de empresas multinacionais nos países em desenvolvimento. Neste artigo foram sugeridas algumas áreas de pesquisa, como: os impactos econômicos, sociais, culturais e éticos da biogrilagem, bem como estudos comparativos de países que enfrentam este tipo de ameaça. Entende-se por biogrilagem como os atos não autorizados de utilização comercial e de obtenção de direitos, principalmente patentes - a partir de recursos genéticos e de conhecimentos tradicionais.

Palavras chave: Biogrilagem. Multinacionais. Comércio internacional.

\footnotetext{
1Doutorado em administração, Professora e pesquisadora do Programa de mestrado/doutorado em administração da UNINOVE, claudiaraac@uol.com.br

${ }_{2}^{2}$ Doutorado em administração, Professora e pesquisadora do Programa de mestrado/doutorado em administração da UNINOVE, jnohara@uol.com.br

${ }_{3}$ Doutorado em engenharia de produção, Professor e pesquisador do Programa de mestrado em Desenvolvimento Regional e Meio Ambiente da UNIARA, hermosilla@linkway.com.br

${ }^{4}$ Doutorado em engenharia de produção, Professora e pesquisadora do Programa de mestrado em

Desenvolvimento Regional e Meio Ambiente da UNIARA, e-chiari@uol.com.br
} 


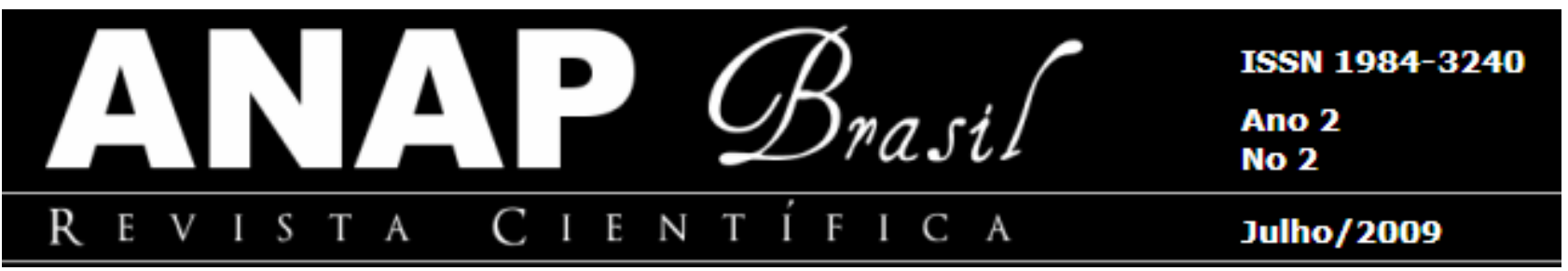

\section{INTRODUÇÃO}

Há aproximadamente 50 anos, a área de administração começou a preocupar-se com as conseqüências para com a sociedade provocadas pelas práticas empresariais, em função dos prejuízos sofridos pelos consumidores. Esses questionamentos tomaram corpo à proporção em que os resultados do comportamento empresarial eram contabilizados pela sociedade, causando danos aos consumidores, como por exemplo, os incidentes com a talidomida (SHETH, GARDNER e GARRETT, 1988).

Atualmente, determinadas áreas das ciências sociais aplicadas, dedicam-se a investigar diferentes tópicos de estudo, tais como: as conseqüências das ações empresariais, políticas públicas e marketing, satisfação e insatisfação dos consumidores, tendências e padrões de consumo, políticas de desenvolvimento, planejamento regional, industrialização e transferência de tecnologia (NASON, et al, 1986).

O objetivo deste ensaio teórico é fomentar a discussão a respeito dos impactos e das conseqüências econômicas e sociais das práticas de biogrilagem por parte de empresas multinacionais nos países em desenvolvimento.

Entende-se por biogrilagem como os atos não autorizados de utilização comercial e de obtenção de direitos, principalmente patentes - a partir de recursos genéticos e de conhecimentos tradicionais (CARVALHO, 2003).

Esta área de investigação tem valiosa implicação prática não somente para os planejadores públicos de países em desenvolvimento, como também para entidades sociais que visam o bem estar de comunidades locais. Pesquisas nesta área de conhecimento também trazem contribuições para a reflexão sobre a ética organizacional.

Além disso, vale ressaltar que apesar do tema biogrilagem estar presente na mídia nos últimos anos, a pesquisa acadêmica relacionada ao tema é praticamente inexistente na área de administração de empresas no Brasil. Por outro lado, o Brasil é um dos países que está mais exposto às ações de biogrilagem (IZIQUE, 2003). Assim, pesquisa relacionada a este objeto é de extrema importância para o país. Por outro lado, é pouco 


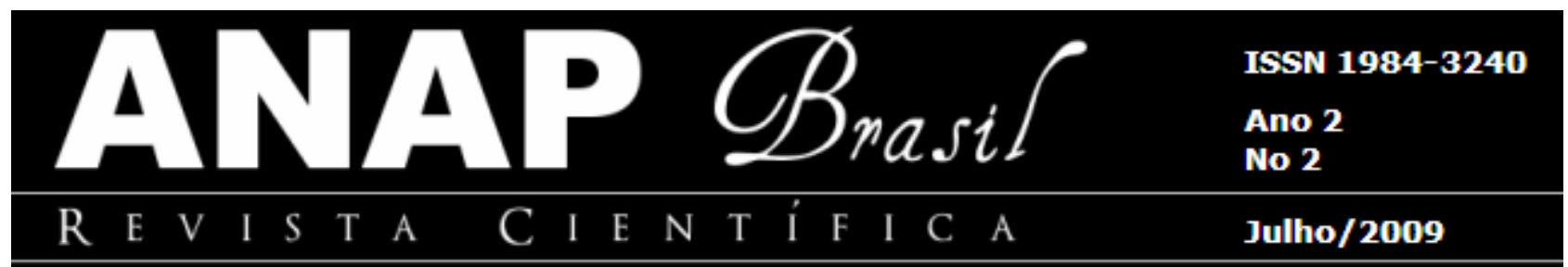

provável que os países desenvolvidos tenham interesse em engendrar pesquisa em biogrilagem já que não estão sendo vítimas desta prática empresarial.

No caso específico do Brasil, o papel de proteção aos recursos genéticos torna-se extremamente complexo em função de suas características geodemográficas. O caso da área amazônica pode ser tomado como exemplo dessa complexidade, em função de seus 13 mil quilômetros de fronteira terrestre e oceânica, 5 milhões de quilômetros quadrados de área e aproximadamente 19 milhões de habitantes na região, sem contar a parcela flutuante composta por turistas, pesquisadores, comerciantes, dentre outros. Como se tal cenário não fosse suficiente, o agravante de uma presença quase nula por parte do estado na proteção de suas fronteiras, aliado a enorme desigualdade na distribuição de recursos financeiros para pesquisa e desenvolvimento regional (em torno de $1 \%$ do orçamento total gasto pelo país para tal fim é destinado à região amazônica, por exemplo), fazem com que a solução para os problemas de biogrilagem, torne-se cada vez mais improvável (FONSECA, 2008).

\section{A BIOGRILAGEM}

O termo biopirataria tem sido utilizado para nomear as práticas não autorizadas de utilização comercial e de obtenção de direitos de propriedade intelectual - como as patentes - a partir de recursos genéticos e de conhecimentos tradicionais associados (CARVALHO, 2003). No entanto a Ompi (Organização Mundial da Propriedade Intelectual) acredita que o nome biogrilagem é mais apropriado pelos seguintes motivos: 1) a palavra biopirataria significa atos ilegais. No entanto, nem todas as práticas designadas por biopirataria são ilegais, já que na maior parte das vezes não há legislação relacionada ao acesso a recursos genéticos; 2) A partir da criação do acordo Trips (Trade Related Intellectual Property Rights) do Gatt (General Agreement on Tariffs and Trade) o termo biopirataria refere-se às infrações ao direito do autor. Contudo, neste novo tipo de pilhagem o termo está relacionado principalmente a marcas e patentes. 3) a palavra biogrilagem é mais adequada porque "significa a reivindicação privada de terras que pertencem a outrem ou que são de domínio público" (CARVALHO, 2003: 18). O termo também está relacionado à invasão ou ocupação de propriedade. 


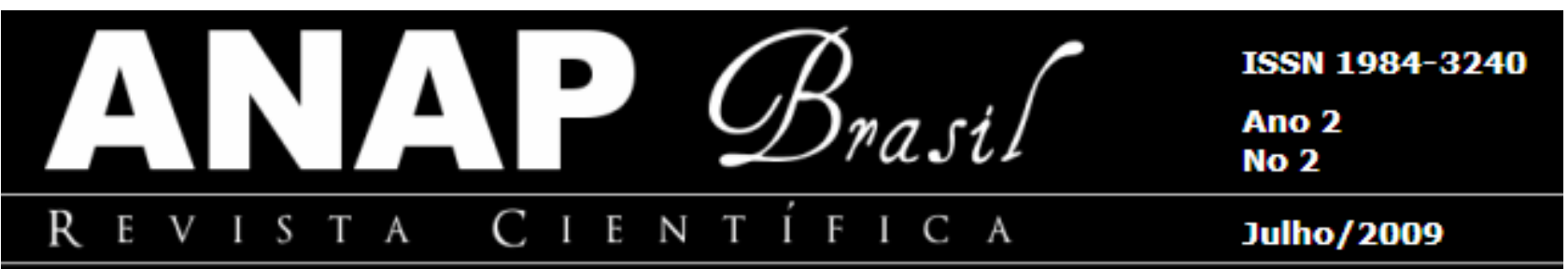

O acordo Trips, acima mencionado, surgiu em 1994 na Rodada Uruguai do Gatt. Este acordo impôs altos níveis de proteção para a propriedade intelectual, principalmente no que se refere a patentes, para todos os países membros da Organização Mundial do Comércio (OMC). Tal acordo privilegia os países que detém investimentos em pesquisa e desenvolvimento (CORREA, 2002). Por outro lado, o acordo Trips foi concebido por três grupos de organizações: o Comitê de Propriedade Intelectual (IPC, sigla em inglês), 0 grupo keidaren e União das Confederações da Indústria e dos Trabalhadores (UNICE, sigla em inglês). O IPC é formado por 12 empresas norte-americanas (Bristol Myers, Dupont, General Electric, General Motors, hewllet packard, IBM, Johnson \& Johnson, Merck, Monsanto, Pfizer, Rockwell e Warnner). A keidanren, por sua vez, constitui uma federação de empresas japonesas e a UNICE é porta voz oficial das empresas européias (SHIVA, 2000).

A biogrilagem relaciona-se ao acordo Trips, à Organização Mundial do Comércio (OMC) e ao poder das multinacionais porque os recursos genéticos e o conhecimento tradicional de alguns países estão sendo patenteados por empresas multinacionais e essas patentes são estimuladas pelo acordo Trips que é imposto aos membros da OMC. Por outro lado, verifica-se que a OMC é controlada pelo poder das multinacionais.

A questão de patentes para produtos ou processos relacionados à biodiversidade ou conhecimento tradicional está intimamente ligada à interpretação do que é valor. Segundo SHIVA (2000) ao se reconhecer o valor apenas quando se agrega tecnologia e capital, negam-se tanto a criatividade da natureza quanto o conhecimento tradicional. Para a autora, saber que uma planta tem uma determinada propriedade, por exemplo, é um metaconhecimento no domínio público da comunidade local. A partir desse conhecimento, vários processos tecnológicos podem ser utilizados para se obter produtos a partir da planta. Por outro lado, a concessão da patente é uma apropriação indevida da criatividade da natureza, pois implica que a propriedade da planta tenha sido criada pelo detentor da patente. No entanto, a fonte de criação da propriedade é a planta, ou seja, a natureza. Desta forma, segundo a autora, o conceito de inovação por trás das patentes concedidas pela OMC são restritos e tendem a favorecer as empresas multinacionais que detém o capital para investir em novas tecnologias. 


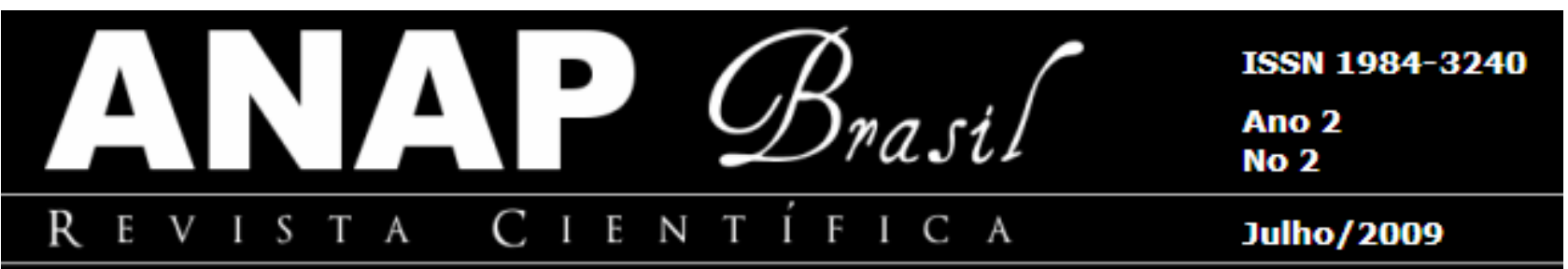

A definição de direito de propriedade intelectual da OMC, legaliza a exploração dos recursos naturais mundiais, uma vez que considera "passível de patente, o conhecimento expresso segundo os cânones da ciência ocidental” (CAPRA, 2002, p. 210).

Por outro lado, ainda segundo CAPRA (2002, p.233), a reforma das instituições como a OMC, o Banco Mundial e o FMI, "não é uma estratégia viável, pois as estruturas, as funções, os objetivos e os processos de funcionamento dessas instituições são fundamentalmente contrárias aos valores fundamentais da dignidade humana e da sustentabilidade ecológica".

Além disso, segundo SHIVA (2000), a modificação da seqüência genética de organismos, outra prática da biogrilagem, não implica na criação de um novo organismo, pois os seres vivos, diferentemente de máquinas, possuem capacidade de autoorganização e auto-reprodução. Por outro lado, quando a auto-organização das espécies passa a ser manipulada e controlada, perdendo a capacidade de adaptar-se e evoluir, a ecologia está ameaçada. Desta forma, a questão da biogrilagem também implica em uma reflexão sobre a ética em relação à natureza.

\section{CONSEQÜÊNCIAS DA BIOGRILAGEM E PROPOSTAS PARA PESQUISAS FUTURAS}

Ativistas sociais interessados no tema de biogrilagem têm alertado para os impactos e as conseqüências econômicas e sociais desta prática nos países em desenvolvimento (SHIVA, 2000).

São vários os impactos econômicos que a biogrilagem pode causar nas localidades atingidas. Um exemplo é a diminuição das atividades empresariais e agrícolas locais, no entanto muitas outros aspectos poderiam ser elucidados com um maior aprofundamento científico, como por exemplo:

- Estudar o nível de desenvolvimento econômico da região e explorar qual é o papel que os produtos e conhecimentos tradicionais que foram patenteados por empresas multinacionais exercem no desenvolvimento local. 


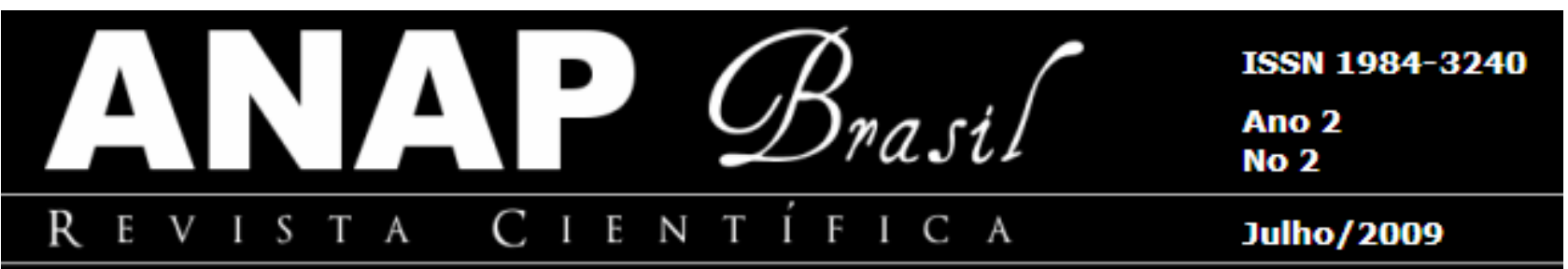

- Examinar a relação entre o emprego local e as atividades relacionadas aos produtos ou conhecimentos patenteados. O cupuaçu, por exemplo, constitui importante fonte de renda para produtores no Acre. A Associação de plantadores Reca, Reflorestamento Econômico, Consorciado e Adensado, reúne 346 famílias, que em 2002 produziram 850 toneladas da fruta e 95 toneladas de semente (IZIQUE, 2003).

- Analisar se houve mudança de atividade industrial na região. Em caso positivo, examinar os motivos. Na Índia, por exemplo, várias empresas multinacionais, que obtiveram patentes relacionadas à biodiversidade do país, instalaram-se na região e propuseram aos fabricantes locais a compra de sua tecnologia, além de tentar convencêlos a não mais fabricar produtos com valor agregado para fornecerem matéria prima para as multinacionais (SHIVA, 2000).

O impacto da biogrilagem, no entanto, não se reduz às localidades onde a biodiversidade é encontrada. Existem sérias conseqüências para as exportações e desenvolvimento econômico do país como um todo. Assim, por exemplo, o Brasil vem enfrentando perdas financeiras nas exportações do Cupuaçu (IZIQUE, 2003). Dessa forma, outra investigação importante é o estudo dos impactos da biogrilagem nas exportações do país atingido.

Por outro lado, as conseqüências sociais da biogrilagem podem ser várias. Entre elas estão o desemprego, a diminuição da renda e o empobrecimento da população local, causados pela diminuição da atividade econômica. Um exemplo de diminuição de renda para os agricultores é a patente de sementes. Neste caso o agricultor é obrigado a comprar sementes toda vez que fizer um novo plantio, não podendo mais reproduzir as sementes para nova lavoura. O desemprego, por sua vez pode vir da redução da produção industrial causada pela diminuição de suas exportações impedidas pelo registro de patentes no exterior. Assim, é importante que se examine a dinâmica do desemprego, e em caso aumento, dimensionar e localizar esse fenômeno. Outras contribuições de pesquisa podem ser estudos sobre a diminuição da renda familiar da região atingida, bem como os impactos nas estruturas familiares, que podem se desagregar como conseqüência da ação da biogrilagem na economia da região.

A pilhagem do patrimônio genético e do conhecimento tradicional nos países de terceiro mundo afeta diretamente as identidades e valores culturais de grupos indígenas, bem como de toda uma nação. Vários casos neste sentido têm sido denunciado por 


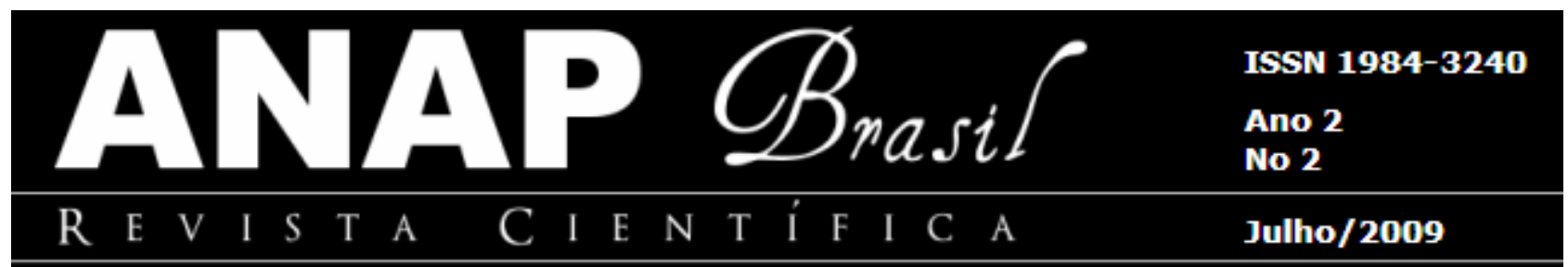

ONG's e ativistas sociais. O nim indiano é um exemplo clássico de como os valores culturais de povos de países em desenvolvimento não estão sendo respeitados. O nim é uma árvore nativa da Índia que é utilizada há mais de dois mil anos no país para se confeccionar pesticidas e remédios. Em algumas regiões da Índia a árvore é considerada sagrada e em várias localidades existe o ritual de se comer os brotos da planta na passagem do ano novo. Além disso, por todo o país o nim é utilizado pela população para proteger os dentes contra bactérias. No entanto, desde 1985 várias multinacionais norteamericanas e japonesas obtiveram patentes à base do nim (SHIVA, 2000).

No Brasil, vários frutos da região Amazônica vem sendo patenteados por empresas transnacionais. O cupuaçu, por exemplo, é utilizado há séculos por grupos indígenas e comunidades locais como uma fonte primária de alimento. O Cipó da Alma, por sua vez, foi patenteado por uma empresa norte-americana. No entanto, a planta é considerada sagrada pelos pajés da Amazônia, pois com ela se produz o "ayahuasca", bebida empregada em cerimônia religiosa para a cura e para contato com espíritos. Outro exemplo é o da polpa do açaí, que teve o nome patenteado, assim como o cupuaçu. $\mathrm{O}$ açaí é largamente utilizada no Brasil na fabricação de sucos e sorvetes. Além disso, outras partes da palmeira, como o palmito, as raízes, o caroço e o cacho, também são tradicionalmente utilizadas pela população. Da mesma forma, vários outros elementos da biodiversidade brasileira vêm sofrendo ação de biogrilagem. É o caso da Andiroba, da copaíba, das sementes do bibiri, utilizadas pelos povos Wapixana de Roraima (TAYLOR, 1998; www.amazonlink.org).

Assim, estudos sobre as conseqüências da biogrilagem nas identidades e valores culturais não só de grupos indígenas, mas também da cultura nacional do país prejudicado por essas ações, constituem outra frente de investigação para efeito de ganho de conhecimento prático e empírico.

Estudos comparativos podem ser de extrema contribuição para esta área de investigação. Vários países vêm sofrendo assaltos da biogrilagem. Seria bastante interessante examinar similaridades e diferenças das conseqüências dessa ação. Outros estudos comparativos que podem ser empreendidos estão relacionados às políticas governamentais utilizadas para impedir as práticas de biogrilagem. Vários países Latino Americanos e Asiáticos vêm tentando encontrar formas para lutar contra a apropriação ilegal de sua biodiversidade genética e conhecimento tradicional que as empresas 


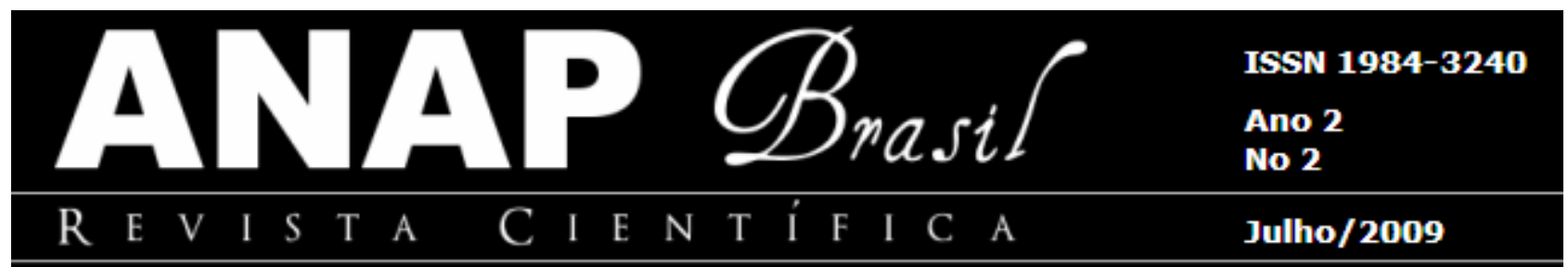

multinacionais estão realizando. Assim, diferentes formas econômicas e legais podem estar sendo encontradas para proteger a biodiversidade. Estudos neste sentido contribuiriam bastante para tais países.

Outro aspecto que merece atenção especial, consiste na investigação sobre a ética que permeia as ações de biogrilagem. Como foi mencionado anteriormente, as patentes de recursos genéticos, da biodiversidade e conhecimento tradicional, negam à criatividade às comunidades que já conheciam as propriedades desses recursos e à própria natureza, reduzindo-as a fornecedoras de matéria prima. Assim, o aprofundamento da análise sobre tais questões é bastante propícia. Outra linha de investigação bastante valiosa é a discussão sobre a ética que permeia a criação de novos produtos baseados em mudanças genéticas de organismos vivos.

Por outro lado, a análise da racionalidade que baseia a concessão de patentes na era atual da biotecnologia também constitui grande contribuição para o estudo da biogrilagem. Um dos aspectos desta discussão é o consenso sobre o que constitui criação de valor.

\section{CONSIDERAÇÕES FINAIS}

O objetivo deste artigo foi discutir e fomentar novas pesquisas sobre os impactos e as conseqüências econômicas e sociais das práticas de biogrilagem por parte de empresas estrangeiras nos países em desenvolvimento.

Foi proposto que diversos fatores poderiam ser considerados nas pesquisas sobre a problemática como os impactos econômicos, sociais, culturais e éticos da biogrilagem, bem como estudos comparativos de países que enfrentam este tipo de ameaça.

A pesquisa sobre a questão da biogrilagem exige um tratamento multidisicplinar, envolvendo as áreas da ciência, como biologia, filosofia, sociologia, antropologia, direito, entre outras, porém carece de uma visão mais holística, capaz de compreender o sistema agregado por meio de análises do comportamento do mercado e suas organizações.

As implicações deste estudo são de extrema importância para os administradores públicos de países atingidos pela biogrilagem. Uma das principais contribuições das 


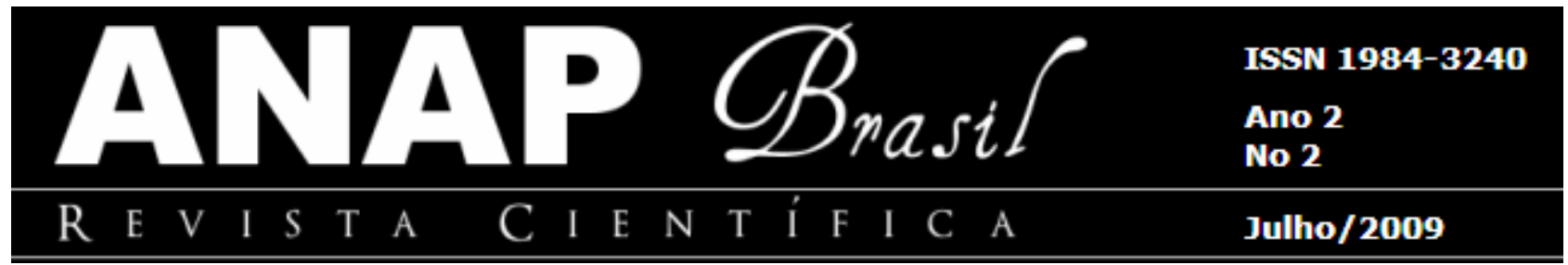

pesquisas nesta área para eles é o conhecimento das proporções dos impactos destas práticas tanto na esfera social quanto cultural e econômica.

\section{REFERÊNCIAS}

CAPRA, Fritjof., As conexões ocultas - ciência para uma vida sustentável, Editora Pensamento-Cultrix Ltda, 2002.

CARVALHO, Nuno Pires de,. Em Defesa da Biodiversidade. p. 17-20. Revista Fapesp, Fev. No 842003.

CORREA, Carlos M., Enquadramento aos Interesses Norte-Americanos. Cadernos Diplô. p. 35-37, No 2, 2002.

FONSECA, Ozório José de M., Biopirataria, uma questão (quase) insolúvel;

Disponível em: <http://www.herbario.com.br.>. Acesso em: 31 mai. 2008.

IZIQUE, Cláudia., Fruta Disputada, Pesquisa Fapesp. p. 14-16, Fev. No 84, 2003.

NASON, Robert et al, Research Directions in Macromarketing: A New England Perspective, Journal of Macromarketing. p. 65-69, Spring, 1986.

SHETH, Jagdish; GARDNER, David M. e GARRETT, Dennis E., Marketing Theory, New York: John Wiley \& Sons, 1988.

SHIVA, Vandana., Biopirataria - A Pilhagem da Natureza e do Conhecimento. Petrópolis: Vozes, 2000.

TAYLOR, Leslie. Herbal Secret's of the Rainforest, London: Prima Publishing, 1998 Disponível em: <http://www.amazonlink.org.>. Acesso em: 25 ago. 2006. 